\title{
Blu-Ray-based micromechanical characterization platform for biopolymer degradation assessment
}

Casci Ceccacci, Andrea; Chen, Ching-Hsiu; Hwu, En-Te; Morelli, Lidia; Bose-Goswami, Sanjukta; Bosco, Filippo; Schmid, Silvan; Boisen, Anja

Published in:

Sensors and Actuators B: Chemical

Link to article, DOI:

10.1016/j.snb.2016.09.190

Publication date:

2017

Document Version

Peer reviewed version

Link back to DTU Orbit

Citation (APA):

Casci Ceccacci, A., Chen, C-H., Hwu, E-T., Morelli, L., Bose-Goswami, S., Bosco, F., Schmid, S., \& Boisen, A. (2017). Blu-Ray-based micromechanical characterization platform for biopolymer degradation assessment. Sensors and Actuators B: Chemical, 241, 1303-1309. https://doi.org/10.1016/j.snb.2016.09.190

\section{General rights}

Copyright and moral rights for the publications made accessible in the public portal are retained by the authors and/or other copyright owners and it is a condition of accessing publications that users recognise and abide by the legal requirements associated with these rights.

- Users may download and print one copy of any publication from the public portal for the purpose of private study or research.

- You may not further distribute the material or use it for any profit-making activity or commercial gain

- You may freely distribute the URL identifying the publication in the public portal 


\title{
Blu-Ray-based micromechanical characterization platform for biopolymer degradation assessment
}

\author{
Andrea Casci Ceccacci, ${ }^{1}$ Ching-Hsiu Chen, ${ }^{2}$ En-Te Hwu, ${ }^{2}$, Lidia Morelli, ${ }^{1}$ \\ Sanjukta Bose, ${ }^{1}$ Filippo Giacomo Bosco, ${ }^{1}$ Silvan Schmid, ${ }^{3}$ and Anja Boisen ${ }^{1}$ \\ ${ }^{1}$ Department of Micro- and Nanotechnology, Technical University of Denmark, DTU Nanotech, Building 345 \\ East, DK-2800 Kgs. Lyngby, Denmark \\ ${ }^{2}$ Institute of Physics, Academia Sinica, Nangang, Taipei 11529, Taiwan \\ ${ }^{3}$ Institute of Sensor and Actuator Systems, Vienna University of Technology, Gusshausstraße 27-29, A-1040 \\ Vienna, Austria
}

\section{Corresponding author ancace@nanotech.dtu.dk}

Degradable biopolymers are used as carrier materials in drug delivery devices. A complete understanding of their degradation behaviour is thus crucial in the design of new delivery systems. Here we combine a reliable method, based on spray coated micromechanical resonators and a disposable microfluidic chip, to characterize biopolymer degradation under the action of enzymes in controlled flow condition. The sensing platform is based on the mechanics and optics from a Blu-Ray player, which automatically localize individual sensors within the array, and sequentially measure and record the resonance frequency of up to twelve resonators within 4 minutes. Such fast and automated measuring technology, combined with the use of thin polymers layers in the degradation experiments, allows to reduce the experimental time needed for degradation studies from 6 weeks to 8 hours. We first present a full characterization of sensor properties and then perform degradation studies of poly(lactic-co-glycolic acid) (PLGA) in steady flow for three different enzyme concentrations. The degradation has been performed in liquid environment. Before each resonator measurement, the measuring chamber has been automatically dried, since the resonator characteristics are much approved when measuring in air compared to liquid. The Comment [FB2]: Honestly I have no obtained degradation profiles are comparable to profiles obtained by conventional approaches, which have shown to require lup to 6 weeks of experimental time frame.

\section{Introduction}

The biopolymer PLGA, poly(lactic-co-glycolic acid) plays a crucial role in biomedical research. PLGA has been FDA approved and is being used in a wide range of biomedical applications such as: grafts, sutures, micro and 
nanoparticles, and scaffold material for tissue engineering applications [1]. PLGA has also been used in commercially available drug delivery devices for treating prostate cancer (Lupron Depot ${ }^{\circledR}$ ) and type-2 diabetes (Byclureon®) [1]. Monitoring mechanical and degradation properties of the biopolymer matrix is crucial in the development of drug delivery devices. PLGA undergoes degradation by a hydrolysis where water attacks the ester bonds present in the PLGA backbone, a reaction which is catalysed in the presence of acid, alkali, salt and specific enzymes [2]. Conventional degradation studies [3] have required large amount of material, which results in expensive and time consuming degradation experiments (days to weeks[3]) limiting experimental throughput and thereby also the statistical significance of the obtained results. These studies are often performed at high temperature or high/low value of $\mathrm{pH}$ [4], in order to accelerate the experimental time frame. Such methods do not comply with demand of high throughput and with the often limited availability of material in the formulation phase. Polymer degradation studies on sub-micrometer thick polymer layers have been performed using QCM [5] and SPR [6]. Although the QCM approach has allowed a time effective analysis, it has shown some limitations: $i$ ) measurements are limited to the thin film regime $[5,7,8]$, ii) thin film properties often differs from the bulk properties [9] and iii) measurements are to be performed onto high homogeneous layer [10]. Micromechanical resonators have already shown their potential as sensors for temperature [11], biomarker detection [12] and material characterization [13-16]. Recently, studies on the behaviour of micrometer-sized thin film biopolymers have been performed [17-19] through the monitoring of the resonance frequency of spray-coated micromechanical cantilevers. The studies demonstrate that micromechanical resonators can characterize polymer films with thicknesses of even several microns and with different surface morphologies. However, so far the reported measurements have been performed in a tedious manner, where polymer coated cantilevers have been taken out of a degradation media (no flow possible), dried and then characterized at given time intervals in a bulky and expensive laser Doppler vibrometer set-up. With such system, measurements and related degradation studies could not be run under flow conditions. Also, the polymer coating introduces experimental challenges since this often causes the cantilevers to bend out of plane, which complicates/impedes read-out.

In this study, we wish to improve and optimize micromechanical resonator measurements for polymer degradation. This includes the development of an automated liquid handling/read-out system and the use of double clamped microcantilevers, henceforth called microbridges (Fig. 1), since these will not bend out of plane when coated with polymers. For degradation studies, the microbridges will be embedded inside a microfluidic chip, where physiological conditions can be replicated and where degradation in flow can be studied. However, 
tailoring an integrated readout for resonance frequency measurements is complex and expensive. Optical readout systems like interferometers are usually bulky and expensive, and they require complex and tedious optical alignment processes. Optical units (OPU) from DVD or Blu-Ray(BR) player represents a low-cost, very flexible, and highly- sensitive [20] alternative, which can be easily embedded in portable and automated system for multiple optical readout purposes [21].

Hence, in order to match the need of a method which can overcome the limitation of the conventional biopolymer degradation studies, and the technological challenges of an integrated readout, we have designed and fabricated a system based on a Blu-Ray pickup head which uses an astigmatic detection technique [20]. The system can automatically scan the position of individual microbridges, arranged in a linear array, and control their actuation through a piezoelectric crystal. The recording of vibrational spectra is also performed automatically by the controlling system software.

Arrays of microbridges have been spray coated [17,22] with a thin $(1-2 \mu \mathrm{m})$ layer of PLGA by an ultrasonic spray coater system. The deposited biopolymer thin film, with a total mass in the sub microgram range, resulted in a drop of the mechanical resonance frequency. Next, the coated microbridges were placed in a microfluidic chip where a steady flow of degradation media was controlled via a syringe pump.

Experiments have been performed using a so-called 'wet and dry' approach (W\&D). In this technique, the degradation has been performed under steady flow condition of degradation media. Prior to resonance frequency measurements, the chamber has been emptied and dried and as a result the measurements were obtained in air (Fig. 2D-E). In air environment, a higher value of the quality factor $(Q)$ and a higher signal to noise ratio (SNR) ensure a reliable monitoring of resonance frequency shifts. The method facilitates degradation in flow and measurements can be obtained at desired time intervals.

\section{Materials and methods}

\subsection{Fabrication of microbridges}

Microbridges have been fabricated with a standard photolithography technique using a two mask process, on 4" silicon-on-insulator (SOI) substrate. The device layer had a thickness of $5 \mu \mathrm{m}$, which defined the thickness of the microbridges. A positive photolithography (1.5 $\mu \mathrm{m}$ AZ-Mir701) step was performed to pattern the device layer and then deep reactive ion etching (DRIE) was used to transfer the photoresist design on the front side to the silicon 
device layer (Fig. 1A). The buried layer of $\mathrm{SiO}_{2}$ acts as a stop layer during etching. A subsequent layer of $\mathrm{SiO}_{2}$

$(200 \mathrm{~nm})$ and $\mathrm{SiN}(200 \mathrm{~nm})$ was grown (Wet Oxidation) and deposited (LPCVD) respectively.

A

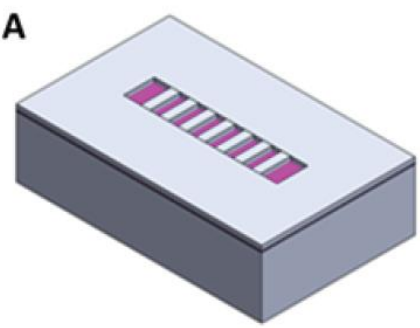

C

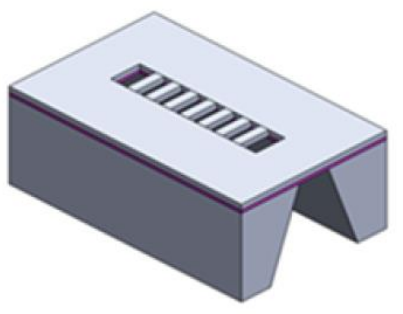

B

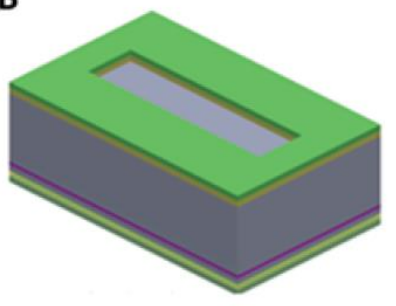

D

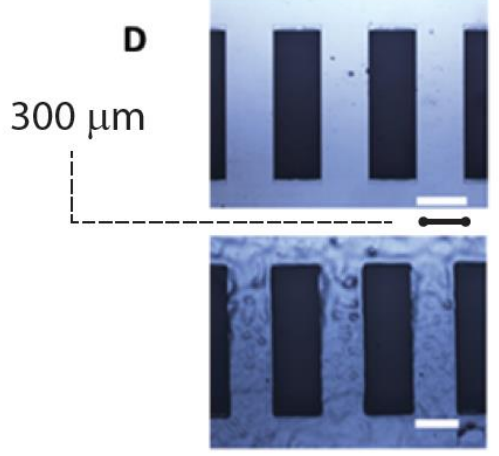

Fig. 1. Schematic view of the fabrication process flow. A deep reactive ion etching has been used for patterning of the device layer; $\mathrm{B} \mathrm{SiO}_{2}$ and $\mathrm{SiN}$ are grown and deposited, respectively, to form a protective layer for the anisotropic etch. They also act as mask on the backside of the wafer, which has been defined by photolithography and subsequent reactive ion etching; $\mathrm{C}$ Anisotropic etching has been done with $\mathrm{KOH}$, which defines the clamping point of the structures. Then, the silicon nitride and the silicon dioxide were removed with phosphoric acid wet etching; D Optical microscope images of the structures before and after the PLGA coating.

A second lithography step has been performed on the backside of the wafer to release and define the clamping points of the microbridges. Windows were opened in the $\mathrm{SiN} / \mathrm{SiO}_{2}$ mask layer using reactive ion etching (Fig. 1B). Subsequently, the wafers were etched in $\mathrm{KOH}\left(80^{\circ} \mathrm{C} 4 \mathrm{~h}: 30 \mathrm{~min}\right)$, and the etch stopped on the buried silicon oxide layer (Fig. 1C). Finally, SiN has been etched away by $\mathrm{H}_{3} \mathrm{PO}_{4}$ at $180^{\circ} \mathrm{C}$ and the $\mathrm{SiO}_{2}$ was removed by $\mathrm{BHF}$. An example of realized microbridges (blank and polymer coated) is showed in Fig. 1D. 

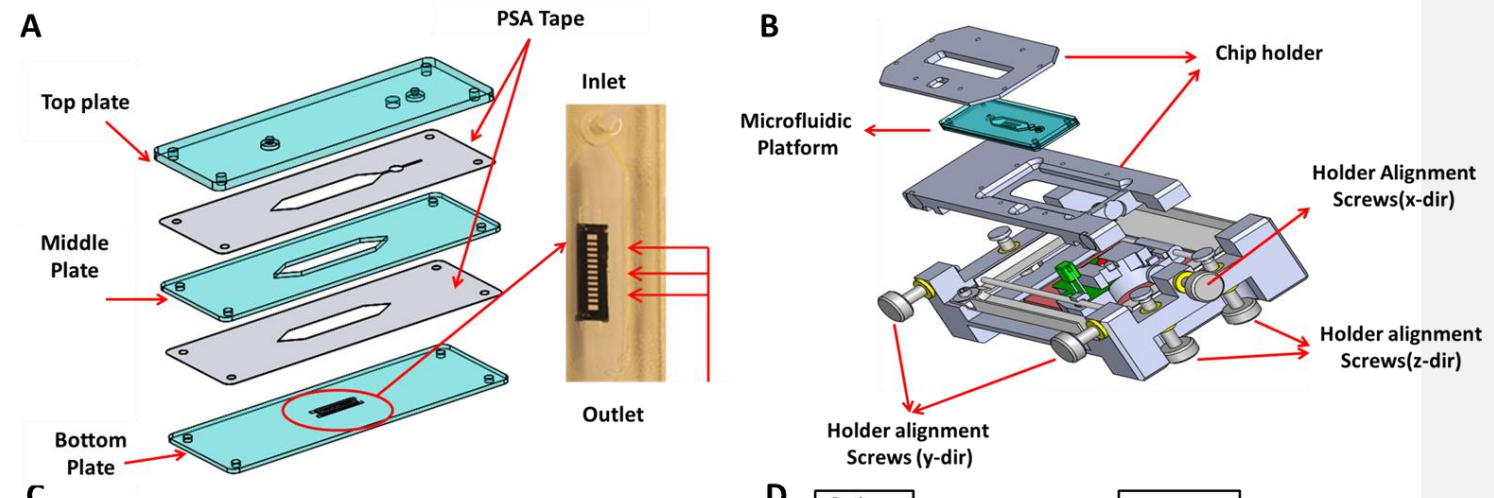

C
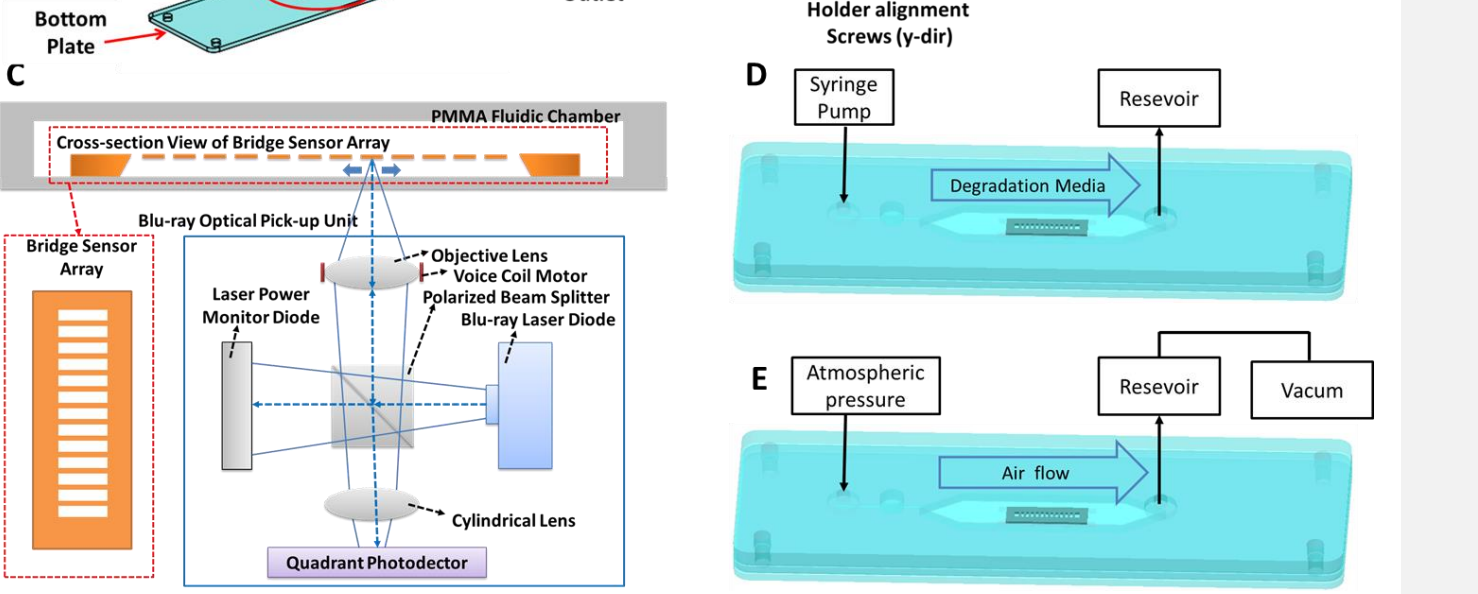

PMMA Fluidic Chamber

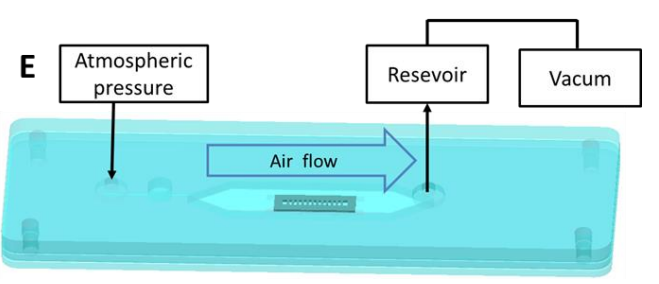

Fig. 2. A: Exploded view of the single-use microfluidc chip and the encapsulation of the resonator. B: Design of the system. The microfluidic plaform is placed inside a chip holder, which can be moved along the three planes thanks to three alignment screws. C: Blu-Ray OPU building blocks. The OPU can move along the microbridges array according to the algorithm explained in the SI.D-E Wet and Dry Approach. D: A syringe pump is connected to the inlet of the chamber and then the degradation media flows inside the camber and ends in the waste reservoir. E: The degradation media flow is stopped and the inlet is unplugged from the syringe pump and left at atmospheric pressure. A negative pressure is generated in the waste reservoir using a vacuum pump, and the measuring chamber is first emptied and then dried with air.

\subsection{Microfluidic platform fabrication}

The microfluidic platform has been composed of 3 plates of PMMA bonded together with pressure adhesive tape

(Fig. 2A). The channel is $500-\mu \mathrm{m}$ wide, $10.5 \mathrm{~mm}$ long and $150 \mu \mathrm{m}$ deep, the chamber in the middle plate defined through laser cutting had total volume of $193 \mu \mathrm{l}$. The microbridges have been fixed in the channel using fluidic connectors that are glued to the platform using PDMS and a Luer-Lock connector has been used to connect to the outlet of a syringe pump. The outlet has been connected to a waste chamber. A vacuum pump has been used to create a negative pressure in order to empty the chamber. 


\subsection{Polymer coating and degradation studies}

Exacta Spray Coater (Sonotek, USA) has been used to coat the microbridges [16,17,22]. The parameters for spray coating microbridges have been optimized using the methodology [22] and the parameters found in our previous works [17].

The ultrasonic spray nozzle was actuated at a frequency of $120 \mathrm{kHz}$ with a generator power of $1.3 \mathrm{~W}$. Compressed nitrogen flow was maintained at 0.06 bar for focusing the flow of the sprayed solution to the substrate. The infusion rate of PLGA solution ( $0.5 \%$ wt. in dichloromethane) was set at $0.05 \mathrm{ml} / \mathrm{min}$. The microbridges to spray nozzle distance was kept constant at $15 \mathrm{~mm}$. The microbridge arrays are composed of 12 bridges, of which 4 are left uncoated and used as references, see Fig. 1D. Hundreds of nanograms of polymer have been sprayed as it was shown in the results section. PLGA undergoes hydrolytic degradation catalysed by the presence of an enzyme [2]. Here we test the effect of the enzymatic reaction of Proteinase-K in three different concentrations $\left(20-50-100 \mu \mathrm{g} / \mathrm{ml}\right.$ in Tris- $\mathrm{HCl}$ buffer solution $\mathrm{pH} 8.6$ at $\left.23^{\circ} \mathrm{C}\right)$ in steady flow. We have further compared these results with the degradation inducted by only water under same flow conditions. The microfluidic chamber was first filled with the degradation media at a flow rate of $200 \mu \mathrm{l} / \mathrm{min}$. When the system has been completely filled, the flow was reduced to $20 \mu \mathrm{l} / \mathrm{min}$. The microfluidic platform has been mounted inside a chip holder (Fig. 2A), and it has been kept tight and clamped by four screws. The chip holder has been placed into a custom-built PMMA box where the temperature has been maintained at $37^{\circ} \mathrm{C}$ using a heat control system (AirTherm ATX, with $0.1^{\circ} \mathrm{C}$ precision) to simulate at best the human physiological condition. The degradation media was degassed for one hour in a vacuum chamber prior to the beginning of the experiment, in order to avoid bubble formation inside the microfluidic chamber.

\subsection{Detection method and system layout}

Astigmatic detection system (ADS) has previously been used to monitor deflection and resonance frequency changes of microcantilevers $[20,21]$. A Blu-Ray (BR) laser diode emits light with a wavelength of $405 \mathrm{~nm}$, focused onto the surface of the microbridges using an internal mirror, collimator and a modified objective lens with high numerical aperture $(\mathrm{NA}=0.6)$, which guarantees a focalized beam and a $\sim 350 \mathrm{~nm}$ size laser spot (Fig. $2 \mathrm{C}$ ).

The reflected laser light from the sample surface (i.e. the microbridges) passes through a polarized beam splitter, a set of cylindrical lenses, and impinges on a quadrant photodetector integrated chip (PDIC). The PDIC consists 
of four single sensors with individual current preamplifiers, which converts photon signal to voltage signal with a bandwidth of $160 \mathrm{MHz}$. Here, a laser power monitor diode is used to monitor laser power. A voice coil motor (VCM) has been used to control the position of the objective lens in order to focus the light at a desired location. Fig. 2B illustrates the system. It is composed of two blocks: the chip holder and a frame where a BR-OPU can move along one direction thanks to a sled motor. Blu-Ray optical pick-up head unit (BR-OPU) is equipped with a VCM that gives a $1 \mu \mathrm{m}$ vertical motion allowing fine adjustment of the focal distance to get the high est possible sensitivity from the ADS. The chip holder is placed on three alignment screws used to do coarse adjustment of the focal distance. The position of the holder can be adjusted in three planes $(x-y, x-z$ and $y-z)$. The working algorithm is shown in the Supplementary Information (SI).

Resonance frequencies were measured in air. Microbridges were actuated by means of a piezoelectric crystal, which was set to linearly sweep a range of frequencies in the vicinity of the theoretically predicted resonance frequency. The values of the resonance frequencies and $Q$ factors were obtained from a Lorentzian fitting performed on the recorded spectra.

\section{Results and discussion}

\subsection{Sensor characterization}

The sensing properties of micromechanical resonators have been characterized in air environment. Mass responsivity of microbridges have been evaluated according to equation 1 . The minimum detectable mass value (equation 2) was calculated considering the deviation of the resonance frequency of multiple measurements on the same microbridge, which has been no greater than $40 \mathrm{~Hz}$. Bridges from the same fabrication batch can differ in the value of the resonance frequency up to $2 \mathrm{KHz}$. However such uncertainty has not affected our scope, since measurements of polymer degradation have been referenced to the same bridge. The formulae used to evaluate the relative frequency shift have been reported in Supplementary Information.

$R=f_{0} / 2 m_{0}(1)$

The minimum detectable mass has been then evaluated considering the product of the mass responsivity and two times the standard deviation. 
$\Delta m \approx(2 \Delta f) R^{-1} \approx 10 n g(2)$

Where $\Delta f$ is the standard deviation of 20 consecutive measurements on the same bridge (data not shown).

Considering the rectangular area on the microbridges where the biopolymer has been deposited, the thickness of the layer can also be calculated. The measured mass of material ranges between $0.45 \mu \mathrm{g}$ and $0.75 \mu \mathrm{g}$, and the corresponding thickness ranges between $1.2 \mu \mathrm{m}$ and $2 \mu \mathrm{m}$. The deposition of PLGA leads primarily to a drop in the resonance frequency, as a change in stiffness can be neglected. In fact, Young's modulus of PLGA is 2 GPa [23] and Young's modulus of silicon is $170 \mathrm{GPa}$. Thus, the flexural rigidity (EI) of the silicon microbridges $(0.5$ $\left.n \mathrm{Nm}^{2}\right)$ is four orders of magnitude times bigger than the flexural rigidity of the polymer film $\left(50 \mathrm{fNm}{ }^{2}\right)$.

Furthermore, it is known that Young's modulus of biopolymers decreases during degradation. In light of this, the observed changes in resonance frequency can be attributed to mass changing phenomena. A typical frequency drop induced by the added polymer layer is shown in Fig. 3 .

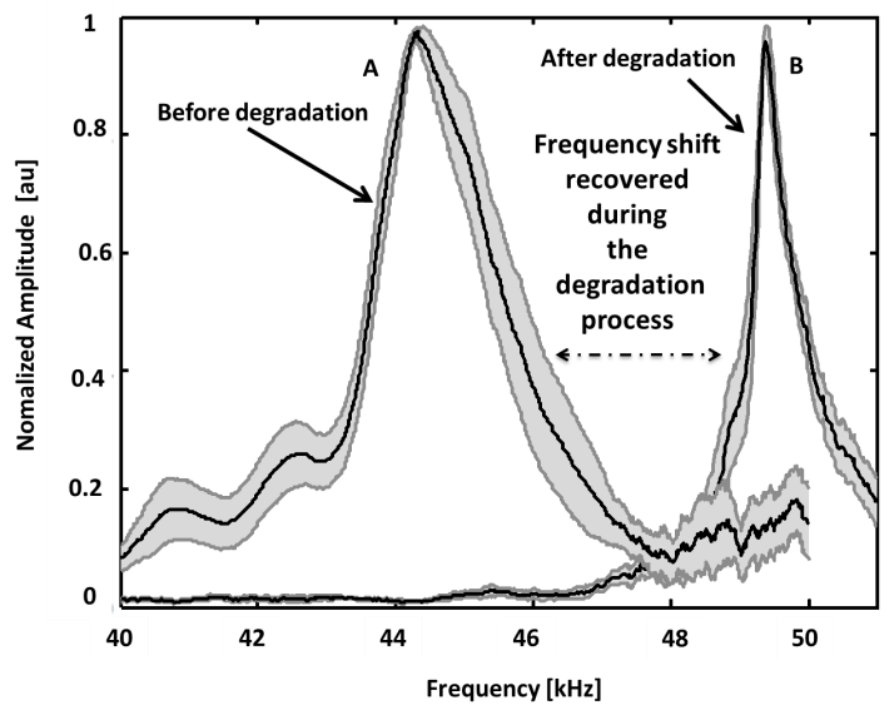

Fig. 3. Frequency shift experienced during biopolymer degradation. A : Resonance peak of a loaded bridge before the degradation process. B: resonance peak of a blank bridge after the degradation process. The shades represent the standard error of the mean $n=5$ 


\subsection{Polymer degradation studies}

This work is, to the best of our knowledge, the first investigation of degradation of PLGA under the catalytic action of Proteinase-K (recombinant, PCR grade obtained from Roche Diagnosis $\mathrm{GmbH}$ ). Coated microbridges have been employed to study the behaviour of PLGA during degradation inducted by the enzyme Proteinase-K in 3 different concentrations. Furthermore, we have studied the degradation induced by only water under the same flow condition, as the polymer can undergo hydrolysis and, at the same time, the shear stress due to the flow might induce some mass removal from the biopolymer layer.

The deposition of a layer of PLGA has led to a drop in the resonance frequency that ranges between $8 \%$ and $12 \%$, depending on the microbridge characterized. This large observed deviation is likely due to the nonuniformity of the coating from chip to chip, and, to a minor extends, to geometrical variations of the bridges after the cleanroom microfabrication.

Fig. 4 shows the results of a degradation experiment performed with the W\&D approach. The temperature fluctuation has been monitored through the evaluation of the relative frequency shift of uncoated bridges. Temperature was seen to be constant within the experimental time frame.

To monitor degradation, the resonance frequency has been measured at regular intervals of time according to the degradation rate expected for a certain enzyme concentration. Three different concentrations have been tested, with a steady flow of $20 \mu \mathrm{l} / \mathrm{min}$.

Enzyme concentrations of 50 and $100 \mu \mathrm{g} / \mathrm{ml}$ have not led to any remarkable differences in the degradation profile. However, a lower enzyme concentration of $20 \mu \mathrm{g} / \mathrm{ml}$ has led to longer degradation time. The hydrophilicity of PLGA, due to the presence of the glycolic unit, triggers the degradation process in the early phase (already in the first hour of experiment), which has been not observed for PDLLA [17].

We have previously shown that Tris- $\mathrm{HCl}$ did not trigger any kind of degradation on a poly-lactade polymer (PDLLA)[17]. Here we have tested the effect of Tris-HCl on PLGA (Fig 4D) which instead have shown to degrade the polymer within 36 hours, even if the degradation was triggered only after 18 hours. The complete degradation profile of the polymer under the action of the Tris- $\mathrm{HCl}$ is shown in the supplementary information. Furthermore, we have monitored the frequency shift of coated microbridges which have been exposed to a water flow of $20 \mu \mathrm{l} / \mathrm{min}$. Although the relative frequency shift fluctuates at the different measurements parts the magnitude of such 
fluctuation is within the uncertainty of the measurement. The water is seen not to trigger any biopolymer removal and degradation within the 12 hours of experimental time frame, as illustrated in Fig. 4D. The relative frequency shift in fact is maintained constant for the full 12 hours of experiment. The procedure used for monitoring enzymatic degradation is also used in this case. We can thus assert that during the experimental time frame the flow have not influenced the removal of PLGA from the bridge surface, this results has also been confirmed through optical microscope imaging, Fig. 5C.

The relative frequency shift profiles have shown similarities to the weight loss profile previously shown on bulky amount of PLGA under the action of trypsin[3]. Fig. 5A shows how the polymer has been removed during the degradation process. Mass sensivity of micromechanical resonator has a spatial dependence, thus real time estimation of the actual amount of material which is loading the microbridges at a certain time step requires complex techniques [24]. Although both trypsin[3] and Proteinase-K are serine protease, a direct comparison of their degradation rate might lead to an inappropriate conclusion. However, we can see that we are able to perform similar type of experiments to explore degradation mechanisms in just a few hours (see Fig. 6B). Furthermore, we want to emphasize that due to the ability of our system to perform simultaneous measurements we are able to investigate a large number of samples, improving the statistics and facilitating simultaneous studies on different materials. 
A
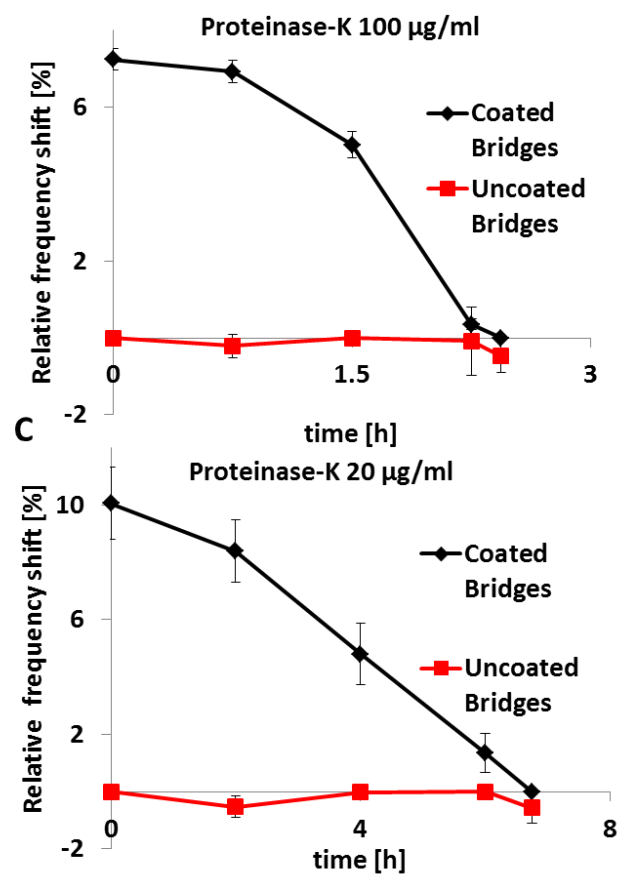

B
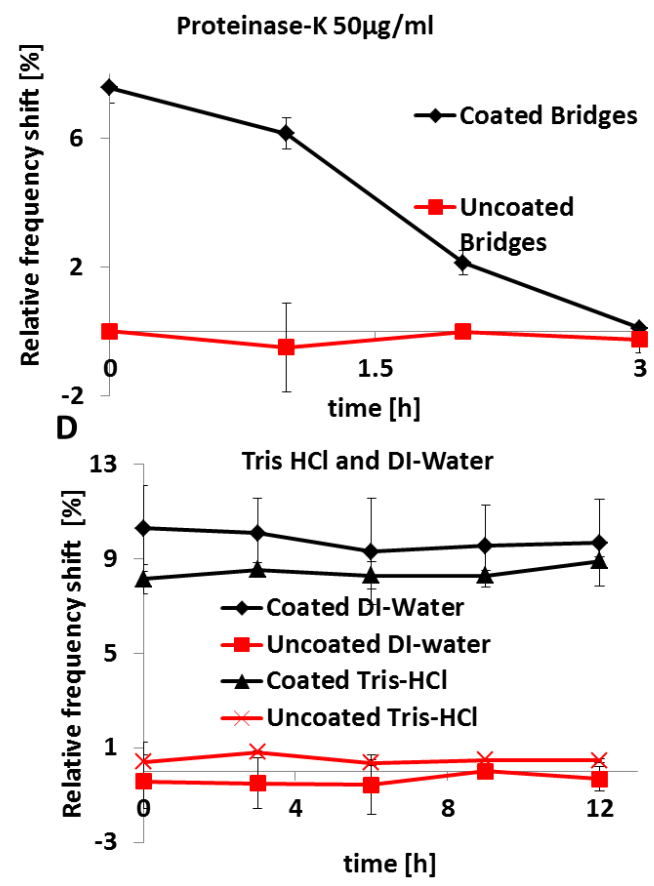

Fig. 4. Degradation profile obtained from different proteinase concentration of A: $100 \mu \mathrm{g} / \mathrm{ml}$; B: $50 \mu \mathrm{g} / \mathrm{ml}$; C: $20 \mu \mathrm{g} / \mathrm{ml}$. D: Relative frequency shift measured when the degradation media is substituted by water and Tris- $\mathrm{HCl}$. Red curves shown the relative frequency shift on the uncoated bridges used as reference. 


\section{Effect of Proteinase- $\mathrm{K} 50 \mu \mathrm{g} / \mathrm{ml}$ at $20 \mu \mathrm{l} / \mathrm{min}$}
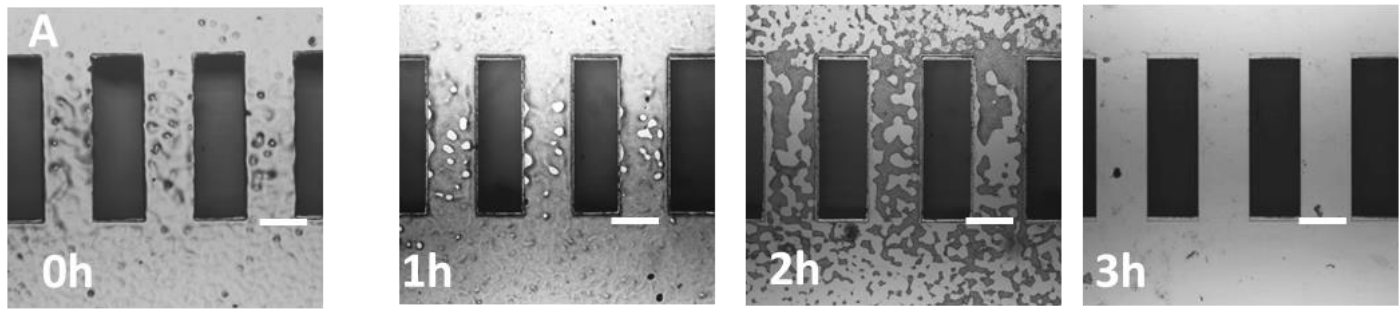

\section{Effect of Tris- $\mathrm{HCl}$ at $20 \mu \mathrm{l} / \mathrm{min}$}
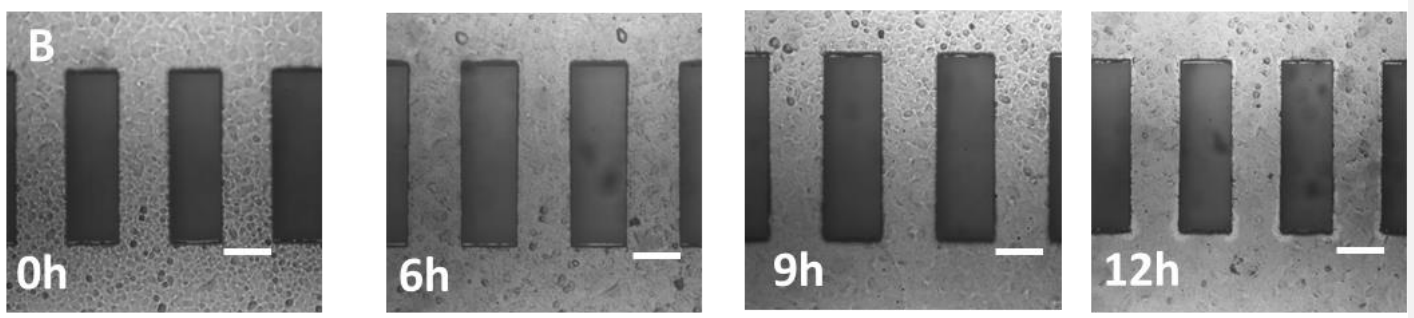

\section{Effect of Water flow at $20 \mu \mathrm{l} / \mathrm{min}$}
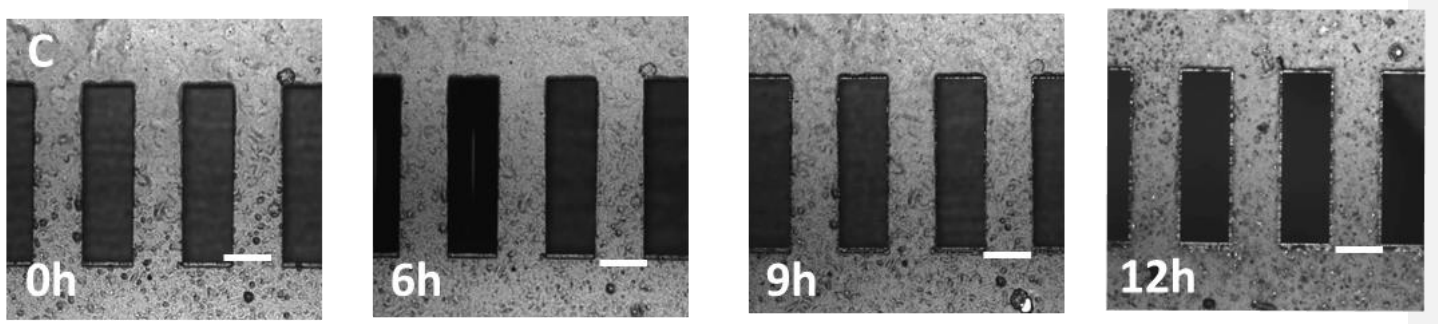

Fig. 5.Optical microscope images of coated microbridges which have undergone to degradation experiments. A Bridges exposed to $50 \mu \mathrm{g} / \mathrm{ml}$. After 3 hours the polymer was completely removed from the surface of the resonator, the few spot are clearly far beyond the detection limit of the resonator. B Bridges exposed at a flow of Tris- $\mathrm{HCl}$ at $37^{\circ} \mathrm{C}$ at $2 \mu \mathrm{l} / \mathrm{min}$.C Bridges exposed at a flow of DI water at $20 \mu \mathrm{l} / \mathrm{min}$. White scale bar $300 \mu \mathrm{m}$.

\subsection{Degradation rate}

The mean degradation rate for each enzyme concentration has been derived considering the initial mass deposited on the microbridges and the time needed to reach the $0 \%$ in the relative frequency shift curves.

Proteinase-K does not possess a specific site to recognize the polyester [5]. The concentration of enzyme 
reaches the saturation level between $50 \mu \mathrm{g} / \mathrm{ml}$ and $100 \mu \mathrm{g} / \mathrm{ml}$ [5]. When the saturation level is reached, higher concentrations do not lead to any faster degradation as the substrate is completely covered by the enzyme.

The degradation rates per unit area are in the same order of magnitude of the $25 \mu \mathrm{g} / \mathrm{cm}^{2} \mathrm{~h}$ reported in literature [3], where the degradation of thick films $(200 \mu \mathrm{m})$ of PLGA has been studied under the action of trypsin (degradation rate of $67 \mu \mathrm{g} / \mathrm{cm}^{2} \mathrm{~h}$ ). This conclusion is obtained by evaluating the amount of material they have analysed and considering the time needed for reaching the $0 \%$ in our weight loss curve. In Fig. 6 we have compared the degradation rate observed in our work with the degradation rate obtained by [5] who studied the degradation rate of PDLLA under the action of Proteinase-K. Besides a difference of two orders of magnitude due to the faster degradation of PLGA because of its hydrophilicity, we may notice that the degradation rate it has seemed to reach a plateau around $100 \mu \mathrm{g} / \mathrm{ml}$.
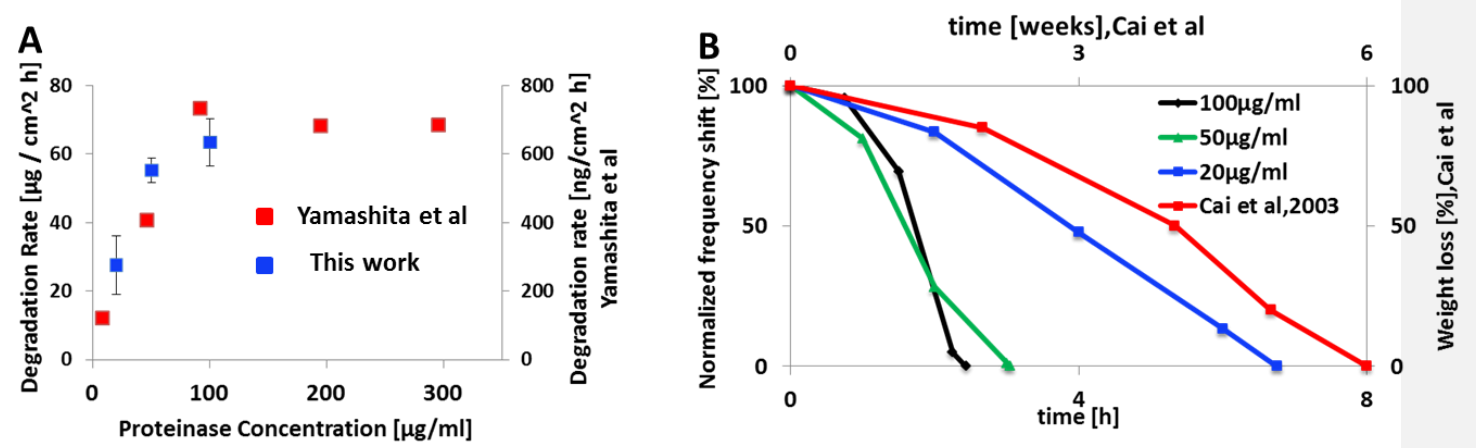

Fig. 6. A Degradation rate dependence from the proteinase concentration. The profile seems to resemble the profile shown from Yamashita et al. B Normalized frequency shift (error bar omitted) and comparison with weight loss curve from Cai et al.

\section{Conclusion}

We have developed and tested an automatic platform aimed to characterize the dynamic characteristics of microbridges and their employment as sensors for monitoring biopolymer degradation. The integration of a microfluidic platform allowed characterizing PLGA degradation under steady flow conditions in a Proteinase-K degradation buffer. The simple experimental setup, combined with high level of automation, reduces the time needed to statistically characterize biopolymer degradation. By increasing the parallelization of the microfluidic 
device, it could be possible to study different degradation conditions simultaneously. The fabricated microbridges have allowed us to study degradation in the sub microgram regime. Although, real time monitoring is not actually possible, as in viscous environments the mass responsivity drops beyond the intrinsic noise level of the readout system, the degradation can be easily studied by employing the W\&D method that allows a good time resolution of the investigated phenomena. The combination of the microfluidic setup with the automatic readout platform facilitates an effective evaluation of biopolymer degradation of micrometer-thick biopolymer film by employing micromechanical resonators. Furthermore, the implementation of the microfluidic device has allowed us to simulate a more physiologically realistic condition for polymer degradation. The degradation parameters as well as the degradation profile derived from our approach matches previous study performed over 6 weeks on bulk amount of material. The degradation profile, as well as the degradation rate show similarities with similar works previously done by other groups using bulk amount of material and conventional methods. A full comparison is difficult since the other studies differ in either enzyme or polymer.

\section{Acknowledgments}

The authors would like to acknowledge machine shop in Institute of Physics, Academia Sinica, Taiwan for precision machining. The research leading to these results has received funding from the European Research Council under the European Union's Seventh Framework Programme (FP7/2007-2013) / ERC grant agreement $n^{\circ}$ [320535]. This research is further supported by the Villum Foundation's Young Investigator Program (Project No.

VKR023125). The research is funded by the Danish National Research Foundation (DNRF122) and Villum Fonden (Grant No. 9301)

\section{References}

[1] J.-M. Lu, X. Wang, C. Marin-Muller, H. Wang, P.H. Lin, Q. Yao, C. Chen, Current advances in researcn and clinical applications of PLGA-based nanotechnology, Expert Rev Mol Daign. 9 (2009) 325-341. doi:10.1586/erm.09.15.Current.

[2] H.K. Makadia, S.J. Siegel, Poly Lactic-co-Glycolic Acid (PLGA) as biodegradable controlled drug delivery carrier, Polymers (Basel). 3 (2011) 1377-1397. doi:10.3390/polym3031377.

[3] Q. Cai, G. Shi, J. Bei, S. Wang, Enzymatic degradation behavior and mechanism of poly(lactide-coglycolide) foams by trypsin., Biomaterials. 24 (2003) 629-38. doi:10.1016/S0142-9612(02)00377-0.

[4] L. Xu, K. Crawford, C.B. Gorman, Effects of Temperature and pH on the Degradation of Poly (lactic acid ) Brushes, Macromolecules. 44 (2011) 4777-4782.

[5] K. Yamashita, Y. Kikkawa, K. Kurokawa, Y. Doi, Enzymatic Degradation of Poly ( L -lactide ) Film by Proteinase K: Quartz Crystal Microbalance and Atomic Force Microscopy Study, (2005) 850-857.

[6] L.G. Sun, Z.Y. Xie, Y.J. Zhao, H.M. Wei, Z.Z. Gu, Optical monitoring the degradation of PLGA inverse opal 
film, Chinese Chem. Lett. 24 (2013) 9-12. doi:10.1016/j.cclet.2013.01.012.

[7] K. Yamashita, T. Funato, Y. Suzuki, S. Teramachi, Y. Doi, Characteristic Interactions between Poly(hydroxybutyrate) Depolymerase and Poly[(R)-3-hydroxybutyrate] Film Studied by a Quartz Crystal Microbalance, Macromol. Biosci. 3 (2003) 694-702. doi:10.1002/mabi.200300004.

[8] O. Wolp, D. Johannsmann, Viscoelastic properties of thin ülms studied with quartz crystal resonators, (1997).

[9] G. Reiter, S. Napolitano, Possible origin of thickness-dependent deviations from bulk properties of thin polymer films, J. Polym. Sci. Part B Polym. Phys. 48 (2010) 2544-2547. doi:10.1002/polb.22134.

[10] B.D. Vogt, C.L. Soles, H.J. Lee, E.K. Lin, W.L. Wu, Moisture absorption into ultrathin hydrophilic polymer films on different substrate surfaces, Polymer (Guildf). 46 (2005) 1635-1642. doi:10.1016/j.polymer.2004.11.114.

[11] T. Larsen, S. Schmid, L. Grönberg, a. O. Niskanen, J. Hassel, S. Dohn, a. Boisen, Ultrasensitive string based temperature sensors, Appl. Phys. Lett. 98 (2011) 121901. doi:10.1063/1.3567012.

[12] G. Wu, R.H. Datar, K.M. Hansen, T. Thundat, R.J. Cote, A. Majumdar, Bioassay of prostate-specific antigen ( PSA ) using microcantilevers, 19 (2001).

[13] C. Yim, M. Yun, S. Kim, N. Jung, S. Lim, M. Lee, Nanomechanical Thermal Analysis of Indium Films Using Silicon Microcantilevers Nanomechanical Thermal Analysis of Indium Films Using Silicon Microcantilevers, Jpn. J. Appl. Phys. 07 (2012) 0-4.

[14] S. Bose, S. Schmid, T. Larsen, S. Sylvest Keller, A. Boisen, K. Almdal, Micromechanical fast quasi-static detection of $\alpha$ and $\beta$ relaxations with nanograms of polymer, J. Polym. Sci. Part B Polym. Phys. 53 (2015) 1035-1039. doi:10.1002/polb.23745.

[15] S. Bose, S. Schmid, T. Larsen, S.S. Keller, P. Sommer-Larsen, A. Boisen, K. Almdal, Micromechanical string resonators: Analytical tool for thermal characterization of polymers, ACS Macro Lett. 3 (2014) 5558. doi:10.1021/mz400470n.

[16] S.S. Keller, L. Gammelgaard, M.P. Jensen, S. Schmid, Z.J. Davis, a. Boisen, Micromechanical sensors for the measurement of biopolymer degradation, Proc. IEEE Int. Conf. Micro Electro Mech. Syst. (2011) 457-460. doi:10.1109/MEMSYS.2011.5734460.

[17] S. Bose, S.S. Keller, A. Boisen, K. Almdal, Microcantilever sensors for fast analysis of enzymatic degradation of poly (d, I-lactide), Polym. Degrad. Stab. 119 (2015) 1-8. doi:10.1016/j.polymdegradstab.2015.04.021.

[18] N. Jung, H. Seo, D. Lee, C.Y. Ryu, S. Jeon, Nanomechanical Thermal Analysis of the Glass Transition of Polystyrene Using Silicon Cantilevers, Macromolecules. 41 (2008) 6873-6875. doi:10.1021/ma801539m.

[19] M. del Rey, R. a. da Silva, D. Meneses, D.F.S. Petri, J. Tamayo, M. Calleja, P.M. Kosaka, Monitoring swelling and deswelling of thin polymer films by microcantilever sensors, Sensors Actuators B Chem. 204 (2014) 602-610. doi:10.1016/j.snb.2014.08.021.

[20] E.T. Hwu, S.K. Hung, C.W. Yang, I.S. Hwang, K.Y. Huang, Simultaneous detection of translational and angular displacements of micromachined elements, Appl. Phys. Lett. 91 (2007). doi:10.1063/1.2817750.

[21] F.G. Bosco, E.-T. Hwu, C.-H. Chen, S. Keller, M. Bache, M.H. Jakobsen, I.-S. Hwang, A. Boisen, High throughput label-free platform for statistical bio-molecular sensing., Lab Chip. 11 (2011) 2411-6. doi:10.1039/c1lc20116f.

[22] S. Bose, S.S. Keller, T.S. Alstrøm, A. Boisen, K. Almdal, Process optimization of ultrasonic spray coating of polymer films., Langmuir. 29 (2013) 6911-9. doi:10.1021/la4010246.

[23] P. Gentile, V. Chiono, I. Carmagnola, P. V Hatton, An overview of poly(lactic-co-glycolic) acid (PLGA)based biomaterials for bone tissue engineering., Int. J. Mol. Sci. 15 (2014) 3640-59. doi:10.3390/ijms 15033640 .

[24] a K. Naik, M.S. Hanay, W.K. Hiebert, X.L. Feng, M.L. Roukes, Towards single-molecule nanomechanical mass spectrometry., Nat. Nanotechnol. 4 (2009) 445-450. doi:10.1038/nnano.2009.152. 
